\title{
PEREMPUAN DALAM SISTEM BUDAYA SUNDA (Peran dan Kedudukan Perempuan di Kampung Geger Hanjuang Leuwisari Tasikmalaya)
}

\author{
ISTI'ANAH \\ Fakultas Syari'ah Institut Agama Islam Cipasung Tasikmalaya \\ istinaza@gmail.com
}

\begin{abstract}
ABSTRAK
Penelitian ini akan menguak peran peran dan posisi perempuan pada sistem budaya sunda berdasarkan fakta sejarah dan juga realitas pada masa kini. Metode penelitian menggunakan penelitian kualitatiif dengan pendekatan historis dan budaya. Pengumpulan data dilakukan dengan studi literatur dan wawancara. Studi literatur digunakan untuk mencari data seputar isu perempuan pada masa lalu. Fokus penelitian ini di Kampung Geger Hanjuang Desa Linggamulya Kecamatan Leuwisari Kabupaten Tasikmalaya. Responden yang terlibat berjumlah lima orang tokoh masyarakat dari kampung Geger Hanjuang.

Dari hasil penelitian, ditemukan bahwa terjadi pergeseran peran dan posisi perempuan dalam masyarakat di mana perempuan pada masa lalu di Kerajaan Galunggung yang lokasinya di Kampung Geger Hanjuang dapat menempati posisi tertinggi di msyarakat bahkan menjadi seorang resi atau guru agama. Fakta yang terjadi saat ini di Kampung Geger Hanjuang adalah perempuan masih diposisikan sebagai pengurus urusan rumah tangga, melayani suami dan mengurus anak. Pergeseran kiprah perempuan ini disebabkan oleh beberapa pengaruh, Sebagian tokoh mengatakan merupakan akibat dari pertemuan antara budaya Sunda dengan budaya Arab pada masa penyebaran Agama Islam, di mana Budaya Arab sangat patriarkhis. Ada pula yang mengatakan sebagai akibat pengaruh dari masuknya budaya Jawa pada masa penyerangan Mataram ke Wilayah Sunda. Akan tetapi saat ini seiring dengan perkembangan global posisi perempuan di masyarakat mulai merambat naik kembali setara dengan laki-laki yaitu dapat berkiprah di ruang publik, akan tetapi peran perempuan sebagai pengurus domestik tetap ada.
\end{abstract}

Kata Kunci : Perempuan, Budaya, Sunda

\begin{abstract}
This research analyses the roles and positions of women in the Sundanese cultural system based on historical facts and also current realities. The research method used qualitative research with historical and cultural approaches. Data collection was carried out by studying literature and interviews. Literature studies are used to find data about women's issues in the past. The focus of this research is in Kampung Geger Hanjuang, Linggamulya Village, Leuwisari District, Tasikmalaya Regency. The respondents were five community leaders from the village of Geger Hanjuang.

From the results of the study, it was found that there was a shift of women role and position in Galunggung Kingdom, which is located in Kampung Geger Hanjuang. In the past time, women could occupy the highest position in society and even become a Resi or religious teacher. And now, in Geger Hanjuang Village, women are still positioned as caretakers of household affairs, serving their husbands and taking care of children. This shift in women's gait was caused by several influences. Some figures said it was the result of the acculturation of Sundanese and Arabic culture during the spread of Islam, where Arabic culture was very patriarchal. Other said that this was due to the influence of Javanese culture during the Mataram occupation in Sunda region. However, at present, along with the global development, the position of women in society has begun to creep back up to the same level as men, namely being able to take part in the public sphere, but the role of women as domestic administrators remains the same.
\end{abstract}

Keywords: Women, Culture, Sundanese 


\section{PENDAHULUAN}

Perempuan di berbagai belahan dunia menempati posisi yang tidak setara dengan laki-laki pada sistem masyarakat yang patriarchal (Andriana, 2001), yaitu sistem masyarakat yang mengutamakan kaum laki-laki. Misalnya dalam bidang pendidikan, perempuan selalu diabaikan. Suatu keluarga yang memiliki anak laki-laki dan perempuan selalu memberikan pendidikan yang lebih baik kepada anak yang laki-laki dari pada perempuan. Hal ini berdasarkan persepsi mereka bahwa pekerjaan perempuan hanya dalam wilayah domestik, maka perempuan tidak memerlukan pendidikan yang tinggi untuk mengurus wilayah domestik tersebut.

Dalam bidang ekonomi, perempuan selalu mendapatkan upah yang lebih rendah dari pada laki-laki, penghargaan kerja yang kurang, serta beban kerja ganda. Dalam bidang politik, peran perempuan dalam bidang ini sangat minim, salah satu penyebabnya adalah akses politik perempuan sangat dibatasi mulai dari keluarga yang mengharuskan perempuan selalu berada di rumah, dan pandangan bahwa berpolitik adalah urusan laki-laki (Roqib, 2003).

Pada konteks relasi antara laki-laki dan perempuan, di masyarakat kebanyakan, laki-laki seringkali diposisikan memiliki akses lebih, jika dibanding perempuan. Akses sumber daya yang berlebih ini, secara sosial menempatkan laki-laki pada posisi superior dan menjadikan perempuan pada posisi inferior (yang lemah). Dalam realitas sosial, relasi seperti ini laki-laki memiliki peran publik sebagai pencari nafkah keluarga dan dan perempuan hanya memiliki peran di ranah domestik yaitu mengurus anak, suami dan membereskan urusan pekerjaan rumah tangga. Dalam realitas kehidupan juga masih sering dijumpai adanya diskriminasi, eksploitasi dan pelecehan terhadap perempuan. Kondisi yang demikian itu karena ada yang beranggapan bahwa perempuan itu memang diciptakan untuk kepentingan dan kesenangan laki-laki. Opini tentang perempuan dalam sejarah masyarakat, kapanpun dan di manapun, selalu terdapat kesan yang bersifat merendahkan perempuan dan dunia ini menjadi dunia laki-laki.

Kedudukan perempuan dalam budaya sunda misalnya dapat dilihat dari hasil penelitian yang dilakukan oleh Agus Heryana berjudul Mitologi Perempuan Sunda yang menjelaskan bahwa perempuan dalam dunia mitologi Sunda berada pada kedudukan yang terhormat. Kedudukan, harkat, dan martabatnya tidak berada di bawah kekuasaan laki-laki, bahkan dalam halhal tertentu menduduki tempat strategis dalam kerangka melahirkan seorang manusia yang berkualitas (Heryana, 2012). Pembahasan tentang perempuan sangat terkait erat dengan isu gender di mana faktor budaya merupakan salah satu yang dominan dalam pembentukannya. Berdasarkan informasi sejarah, pada masyarakat Sunda Kuno pernah berkembang budaya matriarkhi di mana kaum perempuan memiliki posisi yang lebih tinggi dari laki-laki. Ttradisi dan keyakinan dalam sunda kuno menempatkan posisi perempuan sebagai sosok yang berpengaruh dalam kehidupan manusia. Ada beberapa rujukan yang dapat dijadikan pijakan bahwa perempuan sunda masa lampau memiliki kedudukan yang sangat terhormat, di antaranya: karya sastra. Sastra dapat dijadikan sebagai bahan rujukan berdasarkan 
asumsi bahwa sastra dipandang sebagai gejala sosial, karena karya sastra ditulis oleh pengarang diceritakan oleh tukang cerita, disalin oleh penyalin, sedangkan ketiga subjek tersebut adalah anggota masyarakat. Karya sastra hidup di masyarakat, menyerap aspek-aspek kehidupan yang terjadi dalam masyarakat, yang pada gilirannya juga difungsikan oleh masyarakat (Ratna, 2004, hal. 332-333). Sastra yang ditulis pada kurun waktu tertentu langsung berkait dengan norma-norma dan adat istiadat zaman tersebut (Hartoko, 1989, hal. 23). Karya sastra merupakan simbol kehidupan dari suatu masyarakat tertentu

Salah satu karya sastra yang menggambarkan posisi wanita dalam budaya dan masyarakat Sunda ialah sastra lisan Lutung Kasarung. Karya sastra ini sangat populer di kalangan masyarakat Sunda. Dalam sosialisasinya sering ditampilkan dalam bentuk pantun, gending karesmen, atau sandiwara. Banyak wanita dalam cerita ini menempati tokoh/ figur utama. Salah satunya ialah tokoh wanita Sunan Ambu. Tokoh wanita ini, menurut Ayip Rosyidi, merupakan tokoh tertinggi dalam kosmos orang Sunda, karena dalam ceritanya pujangga yang sakti (empat orang laki-laki) ternyata di bawah perintah Sunan Ambu. Juga para pohaci yang suci berada di bawah Sunan Ambu. Dengan kata lain Sunan Ambu merupakan tokoh tertinggi (Ekadjati, 1984, hal. 155). Sunan Ambu dikisahkan menjadi ketua para dewa di kahyangan dan menjadi decision maker jika ada masalah apapun yang muncul di dalam kehidupan manusia di bumi. Sunan Ambu adalah sosok perempuan gaib penguasa khayangan dalam kepercayaan Sunda buhun. Namun peranannya lebih dari itu, karena sosoknya juga dianggap sebagai "ibu" dari kebudayaan Sunda. Arti Sunan Ambu sendiri di dalam Bahasa Indonesia bisa diartikan sebagai
"Ratu Ibu" atau "Dewi Ibu", yang di dalam mitologi masyarakat Sunda bermakna sebagai "ibu" yang merawat tanah air serta lingkungan hidup yang harus dimuliakan.

Penelitian ini akan membahas tentang peran dan kedudukan perempuan di Kampung Geger Hanjuang, Kampung di mana pada masa lalu merupakan pusat pemerintahan kerajaan Galunggung yang dipimpin oleh seorang Ratu. Peneliti ingin melihat bagaimanakah peran dan kedudukan perempuan secara sosial di masyarakat kampung Geger Hanjuang. Apakah terjadi pergeseran peran dan kedudukan dari masa lalu sebagaimana yang telah digambarkan di atas. Dipilihnya Kampung Geger Hanjuang sebagai lokasi penelitian karena di wilayah inilah berdirinya Kerajaan Galunggung yang di pimpin oleh seorang pemimpin perempuan bergelar Sang Bhatary Hyang. Atas dasar ini maka dapat diambil sebuah pertanyaan apakah kepemimpinan perempuan saat itu menjadikan potret tentang peran dan kedudukan peempuan di masyarakat. Lalu di tarik ke masa sekarang bagaimana tentang peran dan kedudukan perempuan, apakah ada pergeseran ataukah tidak.

\section{METODE}

Penelitian ini menggunakan metode penelitian kualitatif dengan meneliti obyek alamiah melalui pendekatan sejarah. Adapun penggunaan sejarah sebagai sebuah pendekatan dalam penelitian ini adalah mencoba memahami sejumlah peristiwa yang terkait dengan peran dan kedudukan perempuan secara sosial pada masa lalu, dan apa yang terjadi pada masa sekarang. Pengumpulan data menggunakan wawancara mendalam dan juga studi literatur. Wawancara dilakukan terhadap lima orang tokoh masyarakat dengan menggunakan 
teknik snowball sampling. Peneliti melakukan wawancara pertama pada salah satu tokoh masyarakat dan mendapatkan informasi tentang tokoh lain yang dapat diwawancara yang dapat digali informasinya tentang budaya masa lalu dan masa kini terkait isu perempuan ini. Dalam analisis datanya peneliti menggunakan analisa data induktif.

\section{HASIL DAN PEMBAHASAN}

Peneliti melakukan wawancara dengan beberapa tokoh masyarakat di Kampung Geger Hanjuang ini. Tokoh-tokoh masyarakat yang dilakukan wawancara adalah $\mathrm{MH}, \mathrm{J}, \mathrm{FS}, \mathrm{NH}$ dan I. Mengenai peran dan kedudukan perempuan di kampung Geger Hanjuang berdasarkan dari hasil wawancara dengan responden $\mathrm{MH}, \mathrm{N}, \mathrm{NH}$ dan I adalah bahwa untuk di rumah tangga perempuan memiliki peran dominan dalam mengurus rumah tangga dan pemimpin keluarga adalah laki-laki. Akan tetapi untuk di lingkungan masyarakat atau ruang publik perempuan dapat memiliki aktifitas atau bekerja dan berkarya. Tidak ada halangan bagi kaum perempuan untuk mengembangkan dirinya di luar rumah. Akan tetapi keidentikkan perempuan dengan rumah tangga masih menjadi wacana yang dominan. Seorang tokoh masyarakat FS mengatakan bahwa dalam rumah tangganya seluruh pekerjaan domestik dilakukan bersama dan posisi FS dengan pasangannya adalah setara (FS, 2020). Sedangkan MH, $\mathrm{NH}$ dan $\mathrm{N}$ mengatakan bahwa pekerjaan rumah tangga dilakukan bersama akan tetapi lebih dominan istri dan laki-laki atau suami menjadi pemimpin dalam keluarga. Terkait peran dan kedudukan perempuan di masyarakat selain pada kehidupan pribadi lima responden tersebut, mereka mengatakan bahwa di kampung ini hampir mayoritas laki-laki menjadi pemimpin keluarga dan perempuan lebih banyak dominan mengerjakan pekerjaan rumah tangga.
Akan tetapi ada beberapa kasus perempuan yang dominan dalam mencari nafkah keluarga tetapi tetap posisi pemimpin di keluarganya adalah laki-laki sekalipun laki-lakinya ini tidak memiliki penghasilan cukup atau bahkan tidak bekerja (MH, 2020).

Pada masa-masa sebelumnya abad 19 dan awal abad 20 di wilayah sekitar Geger Hanjuang masih berkembang wacana dan juga terjadi di masyarakat bahwa perempuan tidak perlu memiliki pendidikan yang tinggi karena pada akhirnya hanya akan mengurus suami, anak dan rumah tangga. Pada era ini bahkan yang banyak menuntut ilmu adalah kaum prianya. Saat itu berkembang pesantren-pesantren dan mayoritas yang menuntut ilmu di pesantren adalah laki-laki. Banyak perempuan yang menikah dalam usia yang masih sangat muda. Akan tetapi pada masa kini sudah banyak perempuan di sekitar Geger Hanjuang yang dapat menuntut ilmu baik di sekolah ataupun pesantren (NH, 2020).

Jika di lihat dari hal ini dan berdasarkan catatan sejarah pada masa lalu, maka terjadi pergeseran budaya dari matriarkhi atau kesetaraan menjadi patriarkhi dan saat ini dengan banyaknya perempuan yang menuntut ilmu dan beraktifitas berkiprah di ruang publik, posisi perempuan dan laki-laki adalah setara, walaupun untuk di rumah tangga, perempuan tetap memiliki posisi di bawah laki-laki, karena laki-laki dalam pemahaman masyarakat adalah sebagai pemimpin dalam keluarga. Terkait kepemimpinan ini juga ada dua kategori yang pertama pemimpin secara mutlak dalam arti segala keputusan dilakukan oleh suami dan ini menjadi mayoritas, yang kedua keputusan rumah tangga dimusyawarahkan bersama dan keputusan akhir ada di tangan suami. Mengenai nafkah keluarga secara dominan laki-laki di kampung ini yang menjadi penaggungjawabnya. 
Terkait sang Ratu yang merupakan pendiri Kerajaan Galunggung ini tidak banyak yang mengetahuinya. Lima orang tokoh masyarakat di antaranya $\mathrm{MH}, \mathrm{J}, \mathrm{FS}$ dan NH bahkan sama sekali tidak mengetahui jika Kerajaan Galunggung yang lokasinya sangat dekat dengan rumah tinggalnya pernah dipimpin oleh para ratu. Mereka menyangka bahwa seluruh Raja di Kerajaan Galunggung adalah laki-laki. Satu orang tokoh yang merupakan kuncen dari situs Geger Hanjuanglah yaitu I yang mengetahui persis sejarah pendirian dan para Ratu yang pernah berkuasa di Kerajaan ini (I, 2020).

Pembahasan tentang perempuan sangat terkait erat dengan isu gender di mana faktor budaya merupakan salah satu yang dominan dalam pembentukannya. Berdasarkan informasi kesusastraan, pada masyarakat Sunda Kuno jika dilihat dari mitologi perempuan sunda sebagaimana digambarkan dalam penelitianpenelitian tentang mitologi perempuan sunda. pernah berkembang budaya matriarkhi di mana kaum perempuan memiliki posisi yang lebih tinggi dari laki-laki. Tradisi dan keyakinan dalam sunda kuno menempatkan posisi perempuan sebagai sosok yang berpengaruh dalam kehidupan manusia.

Sejarah mencatat bahwa kiprah perempuan sunda masa lalu yang tak terbantahkan. Salah satu tokoh yang dapat dijadikan sebagai panutan adalah Bhatari Hyang, penguasa Kerajaan Galunggung yang merupakan cikal bakal berdirinya kabupaten Tasikmalaya. Bhatari hyang mendirikan Kerajaan Galunggung pada tahun $1111 \mathrm{M}$, ia berkuasa selama kurang lebih lima puluh tahun (1111-1152). Batari Hyang dikenal dengan ajarannya tentang tetekon hirup yang dikenal sebagai Sang
Hyang Siksakandang Karesian, ajarannya ini masih dijadikan ajaran resmi pada jaman Prabu Siliwangi (1482-1521 M) yang bertahta di Pakuan Pajajaran. Kerajaan Galunggung bertahan sampai enam raja berikutnya yang masih keturunan Batari Hyang. Tokoh perempuan ini pula yang dalam kropak 6301 (Sanghyang Siksakandang Karesian) disebutsang sadu jatiatau sang bijaksana atau sang budiman. Pencipta ajaran kesejahteraan hidup yang menjadi pegangan para raja dan rakyatnya Bhatari Hyang merupakah panutan dalam keagamaan dan keyakinan (Sejarah Tasikmalaya, 2020, 6 Juli). Ia juga membangun parit (susuk) untuk menahan serangan dari pihak lawan, hal ini membuktikan bahwa Bhatari Hyang sosok pemimpin perempuan yang memiliki tanggung jawab besar akan keamanan kerajaan dan rakyatnya. Selain Bhatari Hyang masih ada empat ratu lagi setelahnya yang menjadi Ratu memimpin Kerajaan Galunggung secara turun temurun.

Selain Bhatari hyang yang menjadi penguasa kerajaan yang bahkan ajarannya menjadi panutan raja raja dan masyarakat di daerah sunda. Sekitar abad $15 \mathrm{M}$, seorang perempuan bernama Buyut Ni Dawit tercatat sebagai tokoh perempuan yang menulis Naskah dan menjadi salah satu kaum intelektual dari kalangan perempuan pada masanya. Naskah terkenal yang ditulisnya berjudul sewakadarma. Naskah ini tertera pada daun rontal yang ditoreh oleh peso pangot, pisau khusus untuk menulis pada daun, bambu, atau kayu. Huruf dan bahasa yang dipakai adalah Sunda Kuno. Bentuknya puisi. Naskah Sewaka Darma termasuk salah satu dari sepuluh naskah Ciburuy, salah satu kabuyutan pada masa Sunda Kuno. Ciburuy merupakan salah satu

\footnotetext{
${ }^{1}$ Kropak adalah sebuah buku atau tulisan yang terbuat dari daun lontar
} 
kabuyutan tempat menuntut agama kaum intelektual masa dulu, kini terletak di Bayongbong, Garut, Jawa Barat. Buyut $\mathrm{Ni}$ Dawit adalah seorang pertapa perempuan yang bertapa di pertapaan $\mathrm{Ni}$ Teja Puru Bancana di Gunung Kumbang. Berdasarkan isinya, naskah Sewakadarma dapat dianggap sebagai salah satu bukti mengenai pernah berkembangnya aliran Tantrayana di wilayah budaya Sunda pada masa silam. Ajarannya menampilkan campuran aliran Siwa Sidhanta yang menganggap semua dewa sebagai penjelmaan Siwa dengan agama Budha Mahayana. Campuran kedua agama itu masih terjadi dengan "agama pribumi" mengingat ternyata unsure hyang tetap dibedakan dari dewata walaupun tempat kediaman keduanya sama-sama disebut kahiyangan (Apipudin, 2010).

Dyiah Pitaloka Citraresmi yang merupakan puteri Raja kerajaan Sunda yaitu Prabu Maharaja Lingga Buana merupakan salah satu tokoh perempuan sunda yang heroik yang rela mati demi kehormatan rakyat dan kerajaannya. Dikisahkan bahwa sang putrid hendak dipersunting Hayam Wuruk dan berangkat menuju Majapahit. Di tengah perjalanan, sang Patih Gajah Mada memandang bahwa ini merupakan salah satu kesempatan untuk menaklukan kerajaan Sunda dan bersikeras bahwa sang putri tidak akan dijadikan Ratu tetapi hanya selir yang akan dipersembahkan pada sang raja Hayam Wuruk sebagai tanda takluknya kerajaan Sunda terhadap Kerajaan Majapahit. Raja Sunda amat murka dan merasa dipermalukan oleh tuntutan Gajah Mada ini sehingga meletuslah peristiwa pilu yang dinamakan perang Bubat, dimana Dyiah Pitaloka rela mati demi menjaga kehormatan negaranya. (Supriatin, 2018) Keberanian sang Puteri menjaga kehormatan kerajaan dengan cara demikian merupakan suatu keberanian luar biasa.
Berdasarkan fakta sejarah di atas, dalam penelitian ini peneliti mengambil sample pada masyarakat yang hidup di sekitar reruntuhan bekas Kerajaan Galunggung yaitu di Kampung Geger Hanjuang Desa Linggamulya Kecamatan Leuwisari Kabupaten Tasikmalaya. Wilayah Desa Linggamulya berada pada ketinggian $500 \mathrm{M}$ diatas permukaan laut dengan spesifikasi daerah hamparan dataran rendah hingga berbukit. Hamparan tanahnya yang subur sebagai akibat dari letusan gunung berapi Galunggung, maka mayoritas masyarakat desa ini berprofesi sebagai petani.

Kerajaan Galunggung yang didirikan pertama kali oleh seorang perempuan yang menjadi salah satu guru atau resi di Kebataraan Galunggung bergelar Bhatari Hyang. Di samping Bhatari Hyang ini masih ada empat orang Ratu yang memimpin kerajaan secara turun temurun yaitu Ratu Saung Galah, Ratu Galung Sakti, Ratu Sembah Golok, dan Ratu Panyosogan. Bhatari Hyang memiliki nama asli Dewi Citrawati yang di samping menjadi seorang Ratu, Dewi Citrawati juga merupakan seorang Resi atau Guru Agama yang sangat dihormati dan diberi gelar Sang Sadu Jati untuk rakyat dan keturunan-keturunannya, sehingga ajarannya dijadikan ajaran resmi pada masa pemerintahannya dan juga pada masa-masa berikutnya (Danasasmita, 1981).

Potret para Ratu yang menjadi penguasa Kerajaan Galunggung dapat menjadikan cerminan kondisi perempuan pada masa lalu terutama di wilayah kerajaan dan sekitarnya, yaitu Kampung Geger Hanjuang. Bahwa perempuan dapat memiliki peran dan kedudukan yang sangat tinggi di masyarakat pada masa lalu bahkan pada posisi tertinggi dari masyarakat yaitu Resi dan Ratu. Resi adalah guru agama atau pendeta merupakan jabatan tertinggi bagi seseorang yang 'alim atau 
memiliki keilmuan keagamaan yang sangat mumpuni. Selain itu sejarah tentang empat Ratu yang menjadi pemimpin kerajaan pada masa setelahnya mencirikan bahwa kemitrasejajaran antara laki-laki dan perempuan atau bahkan kedudukan perempuan yang lebih tinggi dari lakilaki berlangsung selama beberapa abad. Berdasarkan hal inilah maka beberapa tokoh atau ilmuan mengatakan bahwa pada masa Sunda lampau pernah mengalami sistem budaya matriarkhi. Hal ini tentunya terkait dengan budaya yang terjadi pada masa tersebut. Akan tetapi apakah hal ini kemudian masih menjadi budaya di masa-masa berikutnya maka dapat di lihat kembali dari potret para pemimpin atau Raja-raja yang menjadi penguasa di Kerajaan pada periode-periode selanjutnya. Menurut catatan sejarah, Ratu yang terakhir berkuasa adalah Ratu Panyosogan, maka setelah kepemimpinan Ratu ini seluruh Raja-raja yang berkuasa setelahnya sampai pada periode Sukakerta, kemudian sampai pada era Kebupatian di Sukaraja, Manonjaya hingga kini Tasikmalaya adalah berjenis kelamin laki-laki.

Peneliti melakukan wawancara dengan beberapa tokoh masyarakat di Kampung Geger Hanjuang ini. Terkait sang Ratu yang merupakan pendiri Kerajaan Galunggung ini tidak banyak yang mengetahuinya. Lima orang tokoh masyarakat di antaranya $\mathrm{MH}, \mathrm{J}$, FS dan $\mathrm{NH}$ bahkan sama sekali tidak mengetahui jika Kerajaan Galunggung yang lokasinya sangat dekat dengan rumah tinggalnya pernah dipimpin oleh para ratu. Mereka menyangka bahwa seluruh Raja di Kerajaan Galunggung adalah laki-laki. Hanya satu orang tokoh yang merupakan kuncen dari situs Geger Hanjuanglah yaitu I yang mengetahui persis sejarah pendirian dan para Ratu yang pernah berkuasa di Kerajaan ini. ${ }^{2}$

Terjadi dinamika peran dan kedudukan perempuan, pada masa awal kerajaan Galunggung, perempuan dapat memiliki kedudukan sebagai Resi dan Ratu kerajaan. Setelah kepemimpinan empat ratu di bawah Ratu Bhatari Hyang, Kerajaan Galunggung sampai berakhir pada Era Sukapura dipimpin oleh lakilaki yang tentunya hal ini juga memberikan sedikit gambaran tentang peran dan kedudukan perempuan dalam masyarakat sunda. Berdasarkan dalam perkembangan historiografi dunia, juga Indonesia, termasuk di Tatar Pasundan, dapat dikatakan bahwa sejarah adalah "milik" kaum laki-laki. Tema-tema sentral dalam sejarah dipenuhi dengan tema sejarah politik dan militer yang berkaitan erat dengan masalah kekuasaan dan keperkasaan yang dapat dikatakan "milik" kaum laki-laki (Nina Lubis, 2000). Akan tetapi pada masa lalu ada kekuasaan dan keperkasaan perempuan Sunda yaitu kekuasaan lima Ratu Galunggung di abad 10.

Dalam berbagai literatur tentang kehidupan perempuan yang mengalami pergeseran dari matriarkhi ke patriarki menurut beberapa sumber literatur bermula dari pengaruh budaya luar yang masuk dalam kehidupan masyarakat Sunda. Ada yang mengatakan pergeseran ini terjadi ketika kontak budaya Sunda dengan budaya Jawa, ada pula yang mengatakan ketika kontak dengan dengan budaya Arab yang masuk seiring dengan masuknya penyebaran Agama Islam ke wilayah Pasundan, pada akhir abad ke 16 dimulai dengan tegaknya kerajaan Islam pertama yaitu kerajaan Banten dan Cirebon. Sudah jamak diketahui bahwa sebenarnya perempuan Arab pada masa jahiliyah dianggap makhluk yang sangat rendah, bisa

\footnotetext{
${ }^{2}$ Wawancara dengan MH, N, FS, NH dan I pada 78 Juli 2020
} 
diperjual-belikan bahkan merupakan aib keluarga.

Islam sejatinya yang dibawa oleh Nabi Muhammad hendak mengangkat harkat dan martabat kaum perempuan. Maka pada masa Rasululah masih hidup, perempuan memperoleh kehormatan yang mulia, mereka dapat berperan sebagaimana para sahabat Nabi yang laki-laki. Kaum perempuan dalam budaya Arab jahiliyah menempati posisi marginal bahkan nilainya sama seperti benda tak bergerak yang dapat diwariskan. Memiliki anak perempuan pada masa itu dianggap sebagai aib yang bahkan membunuhnya merupakan suatu hal yang dianggap lebih baik. Ajaran Islam yang dibawa oleh Nabi Muhammad memberikan angin segar terhadap kaum perempuan untuk dapat meningkatkan derajat dan martabatnya setaraf dengan pria. Bahkan Umar bin khtaab pernah berkata : "sebelum Islam datang, kami tidak menganggap terhadap perempuan tetapi ketika Islam datang dan membicarakan perempuan maka sejak saat itu kami menganggap dan memperhatikan perempuan".

Akan tetapi peran perempuan sebagaimana terjadi pada masa Nabi mengalami pergeseran setelah Nabi Muhammad wafat. Puncaknya ketika Muawiyah berkuasa, posisi dan peran perempuan kembali seperti masa jahiliyah. Sehingga teks-teks keislaman klasik (kajian-kajian keislaman yang termaktub dalam kitab-kitab) yang hadir pada masa itu dan yang sampai ke wilayah nusantara sangat bias gender dan bernuasa patriarkhis. Pengaruh dari budaya Arab yang kental akan nuansa patriarkhi ini membuat pergeseran nilai dan kedudukan perempuan dalam fungsi sosialnya di masyarakat. Perempuan dalam budaya lokal Sunda yang telah mendapatkan nilai dan kedudukan setara dan sejajar dengan pria akhirnya mengalami reduksi dalam fungsi sosialnya.
Ketika masyarakat Sunda berusaha menyerap dan menerapkan ajaran agama Islam yang dibawa oleh orangorang Arab sebagai penyiar Agama Islam, maka tanpa bisa dihindari terhadap penyerapan pula budaya Arab terhadap kehidupan masyarakat sunda. Penyerapan suatu budaya tentu saja membawa konsekuensi adanya adopsi terhadap nilai-nilai yang berlaku di dalam budaya tersebut. Mulailah perempuan Sunda mengalami pemasungan-pemasungan dalam memaksimalkan fungsi sosialnya.

Islam bukan menjadi penyebab terjadinya pemasungan-pemasungan tersebut, tetapi pemahaman akan teks Agama Islam yang menyebabkan pergeseran pemahaman dari kesetaraan menjadi tidak setara. Teks-teks keislaman klasik yang masuk seiring dengan masuknya Agama Islam ke wilayah Sunda dengan sendirinya membawa budaya patriarki Arab dalam teks tersebut yang sangat mempengaruhi pola pikir masyarakat Sunda.

Tesis yang menyatakan bahwa pergeseran peran dan fungsi sosial kaum perempuan Sunda akibat dari adanya persentuhan budaya Jawa adalah terjadi ketika Mataram menguasai wilayah Pasundan. Sebagaimana diketahui, Mataram menguasai Priangan selama hampir dua generasi (1620-1670). Menurut Nina lubis, akibat kekuasaan Mataram di Priangan, pengaruh tradisi Jawa ini sangat kuat sekali di tanah Sunda (Lubis, 1998) . Budaya Jawa sangat kental dengan nuansa patriarki. Masyarakat Jawa merupakan masyarakat yang memiliki pembatasanpembatasan tertentu dalam relasi gender yang memperlihatkan kedudukan dan peran laki-laki yang lebih dominan dibanding perempuan. Dalam budaya Jawa yang cenderung paternalistik, laki-laki memiliki kedudukan yang istimewa. Perempuan 
Jawa diharapkan dapat menjadi seorang pribadi yang selalu tunduk dan patuh pada kekuasaan laki-laki, yang pada masa dulu terlihat dalam sistem kekuasaan kerajaan Jawa (keraton).

Dalam budaya Jawa misalnya, diajarkan kalau posisi perempuan sebagai pendamping di rumah (suwargo nurut, neroko katut, artinya kita sekeluarga hanya menumpang pada lakilaki. Bila laki-laki masuk neraka kita pasti ikut terbawa). Sehingga selama hampir dua generasi Mataram menguasai wilayah priangan, selama itu pula terjadi pergeseran peran dan fungsi perempuan Sunda sampai masa-masa sesudahnya sehingga membudaya.

Tesis-tesis yang menyatakan bahwa terdapat pergeseran peran dan fungsi sosial perempuan Sunda seyogyanya tidak menjadikan peran dan fungsi sosial perempuan Sunda khususnya dan perempuan-perempuan di belahan dunia ini menjadi terpasung. Budaya memang sangat besar sekali pengaruhnya dalam memasung perempuan. Sebagaimana diungkapkan Arthur S Nalan, bahwa perbedaan prilaku gender memang tidak sekedar biologi semata, tetapi juga melalui proses sosial dan kultural. Tradisi telah membuktikan bahwa posisi perempuan dalam masyarakat Sunda didudukkan sebagai ordinat bukan sebagai subordinate (Nalan, 2000).

Jika dilihat dari teori kebudayaan, di mana definisi kebudayaan menurut E,B Taylor yang dikutip oleh Soerjono Soekamto adalah suatu kompleks yang mencakup pengetahuan, kepercayaan, kesenian, moral, hukum, adat istiadat dan lain-lain kemampuan serta kebiasaan-kebiasaan yang didapatkan oleh manusia sebagai anggota masyarakat (Soekamto, 1982). Dalam hal ini pada masa lalu di mana perempuan dapat menempati posisi sebagai Resi dan juga Ratu maka dapat diambil kesimpulan bahwa budaya yang berkembang saat itu perempuan dapat menempati posisi tertinngi di masyarakat yang tentunya kebudayaan ini sangat terkait dengan pengetahuan dan adat istiadat. Sebagai seorang Resi, Bhatari Hyang memiliki keilmuan yang sangat dalam terutama terkait peran perempuan dan laki-laki. Pengetahuan dan adat istiadat ini menjadi sumber dari kebudayaan pada masanya.

\section{KESIMPULAN}

Terjadi dinamika peran dan kedudukan perempuan sunda di Kampung Geger Hanjuang Kecamatan leuwisari Kabupaten Tasikmalaya dalam sistem sosial masyarakat. Di masa lalu perempuan dapat menempati posisi tertinggi, perempuan pernah menempati posisi yang sejajar dengan laki-laki bahkan menempati posisi yang lebih tinggi atau disebut sistem matriarkhi. Pada masa di mana sistem patriarkhi memiliki tempat di banyak budaya pada era sebelum 1980 an, hal ini juga terjadi di kampung Geger Hanjuang, ada masa ketika kaum perempuan tidak memiliki kesempatan berkiprah di ruang publik, namun hal ini kemudian bergeser kembali pada masa kini kaum perempuan dapat memiliki peran di ruang publik dan memiliki kedudukan sebagaimana laki-laki di masyarakat. Telah terjadi pergeseran kiprah perempuan dari masa lalu hingga masa kini. Pada masa kini juga telah mengalami pergeseran lagi dari yang sangat kental patriarkhinya sampai saat ini tidak begitu kental nuansa patriarkhinya.

\section{DAFTAR PUSTAKA}

Andriana, V. (2001). Penguasa dan Politik Tubuh, Spirit Revolusi Kaum Feminis Radikal. Jurnal Perempuan, 15.

Apipudin. (2010). Penyebaran Islam Di Daerah Galuh Sampai Dengan Abad 
$K e$-17. Badan Litbang dan Diktat Kementerian Agama RI.

Danasasmita, A. S. (1981). Carita ParaHyangan (Transkripsi, Terjemahan, dan Catatan). Proyek Pengembangan Permuseuman Jawa Barat.

Ekadjati, E. S. (1984). Masyarakat Sunda dan Kebudayaanya. Girimukti Pusaka.

Hartoko, D. (1989). Pengantar llmu Sastra. PT Gramedia.

Heryana, A. (2012). Mitologi Perempuan Sunda. Patanjala, 4, no. 1.

Lubis, N. H. (1998). Kehidupan Kaum Menak Priangan. Pusat Informasi Kebudayaan Sunda.

Nalan, A. S. (2000). Kosmologi

Perempuan Sunda (Suatu Studi Gender dalam Tradisi Lisan dan Tradisi Tulisan di Jawa Barat). Departemen P dan K STSI.

Ratna, N. K. (2004). Teori, Metode, Dan

Teknik Penelitian Sastra (Dari.

Strukturalisme Hingga

Postrukturalisme, Perspektif Wacana Naratif). Pustaka Pelajar.

Roqib, M. (2003). Pendidikan

Perempuan. Gema Media.

Soekamto, S. (1982). Sosiologi Suatu

Pengantar. PT Raja Grafindo

Persada.

\section{Wawancara:}

FS. (2020, Juli 7-8). Peran dan

Kedudukan Perempuan di

Kampung Geger Hanjuang.

(Isti'anah, Interviewer)
J. (2020, Juli 7-8). Peran dan Kedudukan Perempuan di Kampung Geger Hanjuang. (Isti'anah, Interviewer)

J. (2020, Juli 7). Peran dan Kedudukan Perempuan di Kampung Geger Hanjuang. (Isti'anah, Interviewer)

MH. (2020, Juli 7-8). Peran dan Kedudukan Perempuan di Kampung Geger Hanjuang. (Isti'anah, Interviewer)

NH. (2020, Juli 7-8). Peran dan Kedudukan Perempuan di Kampung Geger Hanjuang. (Isti'anah, Interviewer) 